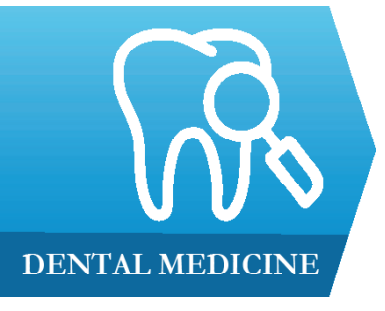

1) Department of Conservative Odontology, Iuliu Hatieganu University of Medicine and Pharmacy, Cluj-Napoca, Romania

2) Department of Prosthetic Dentistry and Dental Materials, Iuliu Hatieganu University of Medicine and Pharmacy, Cluj-Napoca, Romania

DOI: $10.15386 / \mathrm{mpr}-1924$

Manuscript received: 01.10.2020

Received in revised form: 24.10 .2020

Accepted: 07.11.2020

Address for correspondence:

gasparik.cristina@umfcluj.ro

This work is licensed under a Creative Commons Attribution-NonCommercialNoDerivatives 4.0 International License

\title{
Optical properties and masking capacity of flowable giomers
}

Mara Elena Rusnac ${ }^{1}$, Cristina Gasparik ${ }^{2}$, Ada Gabriela Delean ${ }^{1}$, Alexandra Iulia Aghiorghiesei ${ }^{2}$, Diana Dudea ${ }^{2}$

\begin{abstract}
Background and aims. To assess the color, translucency and masking properties of novel flowable giomers.

Methods. Three flowable giomers were used for the fabrication of 1-mm thick samples $(n=126)$ in three different consistencies (Beautifil flow Plus X F00; Beautifil flow F02; Beautifil flow Plus X F03, Shofu Dental Corporation, Japan) and two shades (VITA Classical shade A2 and A3). The relative spectral reflectance was recorded over white, black, C3 (VITA Classical shade C3 simulating a severe tooth discoloration), and a tested-sample colored background. Lightness ( $\left.\mathrm{L}^{*}\right)$, and color coordinates $\mathrm{a}^{*}$ and $\mathrm{b}^{*}$, Relative Translucency parameter $\left(\mathrm{RTP}_{00}\right)$ and masking capacity of $\mathrm{C} 3$ background were calculated; differences in color and translucency were compared with thresholds for perceptibility and acceptability (PT and AT). Statistical analyses used significance tests for paired samples.
\end{abstract}

Results. All tested materials displayed increased values of $\mathrm{L}^{*}$ : for A2 $\quad F 00=86.16( \pm 0.86), \quad F 02=86.39( \pm 0.63), \quad F 03=86.40( \pm 0.63) ; \quad$ for $A 3$ : $\mathrm{F} 00=84.24( \pm 0.58), \quad \mathrm{F} 02=83.34( \pm 0.3), \quad \mathrm{F} 03=84.19( \pm 0.4)$, as well as of RTP: for $\mathrm{A} 2 \quad \mathrm{~F} 00=30.34( \pm 0.88), \quad \mathrm{F} 02=31.37( \pm 0.94), \quad \mathrm{F} 03=31.11( \pm 1.15), \quad$ for $\mathrm{A} 3$ $\mathrm{F} 00=29.64( \pm 1.64), \mathrm{F} 02=30.79( \pm 1.02), \mathrm{F} 03=30.1( \pm 1.26)$. For $\mathrm{A} 2$ samples, the masking capacity was significantly different for all materials, whilst for A3 there were differences only between F00-F03 and F02-F03.

Conclusions. The tested flowable giomers proved high values of lightness and translucency. The color differences between the materials with the same designation and different consistencies were below the perceptibility threshold in most cases. In addition, the differences in relative translucency parameter ranged between the perceptibility and acceptability thresholds. However, all tested flowable giomers had an unacceptable masking capacity for a dyschromic background.

Keywords: giomers, optical properties, translucency, masking capacity, spectroradiometer

\section{Background and aims}

In current dentistry, esthetic considerations are highly important for both the patient and the dentist. A beautiful smile has a significant impact on the quality of life and the self-esteem of individuals [1-5] and, as a consequence, there is a lot of emphasis on the importance of esthetic restorations.

Under these circumstances, the variety of materials, the consistencies, colors, and opacities currently available is vast. For a certain indication of a restorative material, along with other clinical goals, it is desirable to match its color and translucency to the tooth structure, aiming for an optimal esthetic result [6].

The main categories of materials for direct esthetic restorations are composite resins, glass-ionomers, and materials that, through their composition, properties and indications, are at the intersection of these two groups: resin-modified glass-ionomers, compomers, giomers [7-11]. 
Composite resins are made of a versatile mixture of organic and inorganic particles resins, fillers, chemical catalysts, and a coupling agent [7]. The main advantages of composite resins are the possibility to build direct restorations with esthetic results, more conservative tooth preparations, good marginal integrity and wear resistance of restorations, as well as low costs compared to indirect restorations. [8]. Differences in filler content allow for various clinical indications of composite resins. Low viscosity makes the resin easy to handle, but the lower filler content modifies optical and mechanical properties $[8,12]$.

Due to fluoride release, glass-ionomers provide protection from carious lesions and bond chemically to the tooth structure $[11,13,14]$.

Giomers were developed with the desire to combine the esthetics of composites with the antibacterial protection of glass-ionomers and they are available in a wide range of colors classified by the VITA Classical shade guide system in the four hue groups (A, B, C and D, each with subgroups of saturations), with some variations depending on the type of material. Giomers have shown ideal properties for restoring cervical carious and non-carious lesions, one of the main challenges of direct restorative dentistry due to the quality of adhesion at the cervical level [11,15-17]. Moreover, for these lesions, flowable materials would be indicated, as they have higher flexibility and are less likely to be displaced from high-stress areas [18].

Optical properties of flowable giomers are clinically relevant, as the cervical part of teeth is often visible during smiling. This area of the tooth is characterized by a higher opacity and slightly yellowish and reddish shades.

The optical properties to be considered when a restorative material is selected are the color and the translucency. For restorative materials, color is most often coded in the VITA Classical system (A1-A4 reddish brownish shades, B1-B4 reddish-yellowish shades, C1-C4 greyish, D2D4 reddish-grey). However, in dental color research, the CIE $\mathrm{L}^{*} \mathrm{a}$ *b system (Commission Internationale de l'Éclairage) is frequently used to express the color parameters of restorative materials $\left(L^{*}\right.$ represents lightness, whilst $a^{*}$ and $b^{*}$ are the color coordinates in red-green and yellow-blue scale respectively). To overcome the lack of uniformity of the CIEL*a*b color space, the use of the CIEDE2000 system is recommended [19]. Color differences calculated using these systems are linked to the 50:50\% perceptibility and 50:50\% acceptability thresholds, which allow a clinical interpretation of the results [20-22].

In addition to the primary color attributes (hue, lightness, and chroma), there are other, more subtle properties that can have a considerable impact on the final result (translucency, opacity, fluorescence, with translucency being the most important) [23-25].

Translucency is the status between transparency and opacity and is most often expressed as a relative translucency parameter (RTP) $[19,20]$. This parameter is calculated as the color difference of the sample overlapped on a black and a white background. For highly translucent materials, the final optical outcome of the restoration may be affected by a discolored tooth structure [6]. Recently, values for translucency perceptibility and acceptability thresholds were introduced, which allow for the interpretation of the clinical relevance of differences in translucency, in clinical dentistry [26].

It has been shown that the color coordinates of composites with the same designation, originating from different brands can be different. Several authors have shown that the color and translucency depend on the manufacturers and the shade classification $[18,25,27-30]$. To the best of our knowledge, no research has been done to analyze the color and translucency parameter of different consistencies of flowable giomers. In addition, the masking capacity of flowable giomers has not been studied.

The aim of the present study is to compare the color, translucency parameter, and masking capacity among different shades and consistencies of flowable giomers.

The null hypothesis is that there were no differences in color coordinates, translucency parameter, and masking capacity among different flowable giomers with the same color designation.

\section{Methods \\ Sample preparation}

Giomer material with three different flowing properties ("F00 minimal flow", "F03 low flow", "F02 low flow" from Shofu Dental Corporation, Japan) and two different colors (A2 and A3) were used for samples preparation (Table I).

Table I. Composition and characteristics of flowable giomers studied (from manufacturers' instructions - Shofu Dental Corporation, Japan).

\begin{tabular}{|c|c|c|c|}
\hline Name & Consistency & Composition & Code \\
\hline Beautifil flow Plus X F00 & Minimal flow & $\begin{array}{l}\text { Bis-GMA, TEGDMA, Bis-MPEPP, S-PRG filler based on } \\
\text { fluoroboroaluminosilicate glass, polymerization initiator, pigments and others }\end{array}$ & F00 \\
\hline Beautifil flow F02 & Low flow & $\begin{array}{l}\text { Bis-GMA, TEGDMA, S-PRG filler based on fluoroboroaluminosilicate glass, } \\
\text { polymerization initiator, pigments and others }\end{array}$ & F02 \\
\hline Beautifil flow Plus X F03 & Low flow & $\begin{array}{l}\text { Bis-GMA, TEGDMA, Bis-MPEPP, S-PRG filler based on } \\
\text { fluoroboroaluminosilicate glass, polymerization initiator, pigments and others }\end{array}$ & F03 \\
\hline
\end{tabular}

Bis-GMA = bisphenol A diglycidildimethacrylate; TEGDMA = triethylene glycol dimethacrylate; Bis-MPEPP = Bisphenol A polyethoxy methacrylate; S-PRG = Surface pre-reacted glass-ionomer. 
The materials were packed into a round mold (Porcelain Sampler, Smile Line, $\mathrm{CH}$ ) and $1 \mathrm{~mm}$ thick discs were obtained (10 $\mathrm{mm}$ diameter). On the top of the sample a thin glass plate was applied, and the light-curing was performed for 20 seconds (Ivoclar Vivadent Led Edition); 21 specimens were fabricated for each material and for each color (63 samples per color, and 126 specimens in total).

\section{Sample finishing}

Both surfaces of the giomer samples were finished using ultrafine sandpaper (1500 grit). They were then placed into an ultrasonic bath cleaner with distilled water at 40 degrees Celsius and vibrated for 4 minutes, to remove any residues. After finishing, the specimens were stored individually in distilled water, in a dark environment, for 12 hours.

\section{Background samples fabrication}

Beautifil II giomer in 3 different VITA shades, $\mathrm{A} 2, \mathrm{~A} 3$ and $\mathrm{C} 3$, was used for background preparation. The materials were packed into a round mold (Porcelain Sampler, Smile Line, $\mathrm{CH}$ ) and $2.5 \mathrm{~mm}$ thick discs were obtained (10 $\mathrm{mm}$ diameter). On the top of the sample a thin glass plate was applied, and the light-curing was performed for 60 seconds (Ivoclar Vivadent Led Edition).

\section{Reflectance and color measurements}

The relative spectral reflectance between 380$780 \mathrm{~nm}$ at $4 \mathrm{~nm}$ interval was recorded with a non-contact spectroradiometer (SpectraScan PR-655, Photo Research, USA), inside a viewing booth (JUST Normlicht Color Viewing Booth, GmbH, Germany), using a spectrally calibrated reflectance standard (WS-1-SL Diffuse Reflectance Standard, Spectralon Ocean Optics). The illuminating/measuring geometry was diffuse $/ 0^{\circ}$. Measurements of the samples were carried out over black, white, C3, A2, and A3 colored backgrounds (Table 2). Spectral reflectance values were converted into CIE $\mathrm{L} * \mathrm{a} * \mathrm{~b} *$ color coordinates using CIE $2^{\circ}$ Standard Observer and CIE D65 Standard Illuminant (Table II). An optical solution (sucrose solution 73\%) was interposed between the samples and the backgrounds. Three consecutive measurements were performed for each sample.

Table II. CIEL*a*b coordinates of each background, averaged from three measurements.

\begin{tabular}{l|c|c|c|c|c} 
& White & Black & C3 & A2 & A3 \\
\hline L* & 97.14 & 24.60 & 59.81 & 74.29 & 70.94 \\
a* & -0.24 & -0.03 & 5.18 & 4.70 & 7.24 \\
b* & 3.05 & -2.06 & 17.73 & 18.26 & 23.93
\end{tabular}

\section{Color difference calculations}

Color difference values $\left(\Delta \mathrm{E}_{00}\right)$ between the giomer samples (F00, F02, and F03) measured over white background were computed using the CIEDE2000 formula [19]:
$\Delta E_{00}=\left[\left(\frac{\Delta L^{\prime}}{K_{L} S_{L}}\right)^{2}+\left(\frac{\Delta C^{\prime}}{K_{C} S_{C}}\right)^{2}+\left(\frac{\Delta H^{\prime}}{K_{H} S_{H}}\right)^{2}+R_{T}\left(\frac{\Delta C^{\prime}}{K_{C} S_{C}}\right)\left(\frac{\Delta H^{\prime}}{K_{H} S_{H}}\right)\right]^{\frac{1}{2}}$

Where $\Delta \mathrm{L}^{\prime}, \Delta \mathrm{C}^{\prime}, \Delta \mathrm{H}^{\prime}$ represent differences in lightness, chroma and hue between two types of giomer samples; $R_{T}$ is a rotation function that compensates for the interaction between hue and chroma differences in the blue region of the color space; $\mathrm{S}_{\mathrm{L}}, \mathrm{S}_{\mathrm{C}}, \mathrm{S}_{\mathrm{H}}$, are weighting functions that adjust the total color difference for variation in the location of the color difference pair in $\mathrm{L}^{\prime}, \mathrm{a}^{\prime}, \mathrm{b}^{\prime}$ coordinates; and the parametric factors $\mathrm{K}_{\mathrm{L}}, \mathrm{K}_{\mathrm{c}}, \mathrm{K}_{\mathrm{H}}$, are correction factors for experimental conditions and were all set 1 .

Color difference values obtained were compared to the $50: 50 \%$ perceptibility and $50: 50 \%$ acceptability thresholds in dentistry $\left(\mathrm{PT}=0.8 \Delta \mathrm{E}_{00}\right.$ units and $\mathrm{AT}=1.8 \Delta \mathrm{E}_{00}$ units) [22].

\section{Relative Translucency Parameter $\left(\mathbf{R T P}_{00}\right)$}

The relative translucency parameter $\left(\mathrm{RTP}_{00}\right)$ of $1 \mathrm{~mm}$ thick giomer samples was calculated with the CIEDE2000 formula [19] as the difference between the CIE L*a*b* parameters of the giomer samples over the white and the black background; results were compared to the 50:50\% perceptibility and 50:50\% acceptability thresholds for translucency $\left(\mathrm{TPT}_{00}=0.6\right.$ and $\left.\mathrm{TAT}_{00}=2.6\right)[22,26]$.

\section{Masking capacity}

The masking capacity of $1 \mathrm{~mm}$ sample for a $\mathrm{C} 3$ colored background was calculated with the CIEDE2000 formula [19] as the difference between the CIE L*a*b* parameters of the test sample overlapped on a $\mathrm{C} 3$ background and the CIEL*a*b* parameters of the sample placed on a background in the same color, (A2 for A2 samples, and A3 for A3 samples respectively). A high color difference indicates a lower capacity to mask the respective background.

\section{Statistical analysis}

The lightness $\left(\mathrm{L}^{*}\right)$, the chromatic parameters $\left(\mathrm{a}^{*}\right.$ and $\mathrm{b}^{*}$ ), the relative translucency parameter, and the masking capacity for each material type (F00, F02, F03), both in $\mathrm{A} 2$ and $\mathrm{A} 3$ colors, were statistically analyzed using significance tests for paired samples.

In this respect, the values of parameters like mean value, median, mode, upper and lower quartile in order to study the sample with respect to each variable, depending on each material that is used were determined. The level of significance $(\alpha)$ used was $5 \%$ and the confidence intervals for mean value of each variable were determined, for each material. The confidence interval was $95 \%$.

The starting hypothesis (the null hypothesis) is that the mean values do not differ significantly. A one-tailed test was applied.

To perform the above described analyzes, the statistical software Statgraphics Centurion was used. 


\section{Results}

CIE L*a*b* color coordinates of giomers over white background are presented in table III.

Table III. Average CIE L*a*b* values and standard deviations of tested giomers measured over a white background.

\begin{tabular}{|c|c|c|c|c|c|c|}
\hline \multicolumn{4}{|c|}{ A2 } & \multicolumn{3}{|c|}{ A3 } \\
\hline & $\mathbf{L}^{*}$ & $a^{*}$ & b* & $\mathbf{L}^{*}$ & $a^{*}$ & $b^{*}$ \\
\hline F00 & $\begin{array}{c}86.16 \\
( \pm 0.86)^{\mathrm{a}}\end{array}$ & $\begin{array}{c}4.39 \\
( \pm 0.24)^{b}\end{array}$ & $\begin{array}{c}24.83 \\
( \pm 0.58)\end{array}$ & $\begin{array}{c}84.24 \\
( \pm 0.58)\end{array}$ & $\begin{array}{c}6.31 \\
( \pm 0.34)^{d}\end{array}$ & $\begin{array}{c}32.54 \\
( \pm 1.57)^{f}\end{array}$ \\
\hline F02 & $\begin{array}{c}86.39 \\
( \pm 0.63)^{a}\end{array}$ & $\begin{array}{c}4.28 \\
( \pm 0.3)^{b}\end{array}$ & $\begin{array}{c}25.47 \\
( \pm 0.82)^{\mathrm{c}}\end{array}$ & $\begin{array}{l}83.34 \\
( \pm 0.3)\end{array}$ & $\begin{array}{c}6.46 \\
( \pm 0.22)^{\mathrm{d}, \mathrm{e}}\end{array}$ & $\begin{array}{c}30.88 \\
( \pm 0.5)^{g}\end{array}$ \\
\hline F03 & $\begin{array}{c}86.40 \\
( \pm 0.63)^{\mathrm{a}}\end{array}$ & $\begin{array}{c}4.28 \\
( \pm 0.29)^{b}\end{array}$ & $\begin{array}{c}25.47 \\
( \pm 0.83)^{\mathrm{c}}\end{array}$ & $\begin{array}{l}84.19 \\
( \pm 0.4)\end{array}$ & $\begin{array}{c}6.47 \\
( \pm 0.22)^{\mathrm{e}}\end{array}$ & $\begin{array}{c}30.81 \\
( \pm 6.31)^{f, g}\end{array}$ \\
\hline
\end{tabular}

*Same superscript letter in the same column indicate no significant difference $(\mathrm{p}>0.05)$.

The $\mathrm{L}^{*}$ and $\mathrm{a}^{*}$ parameters of the $\mathrm{A} 2$ samples did not differ significantly between the three types of materials $(p>0.05)$. The $b^{*}$ parameter differed significantly for F00-F02 and F00-F03 pairs.

For A3 colored samples, the $\mathrm{L}^{*}$ parameter differed significantly between the three giomers $(p<0.05)$. The highest values were recorded for F00, followed by F03 and F02. The $a^{*}$ parameter differed for F00-F03 materials and $\mathrm{b}^{*}$ differed for F00-F02 materials.

The color differences between all pairs of materials with the same color designation are illustrated in figure 1.

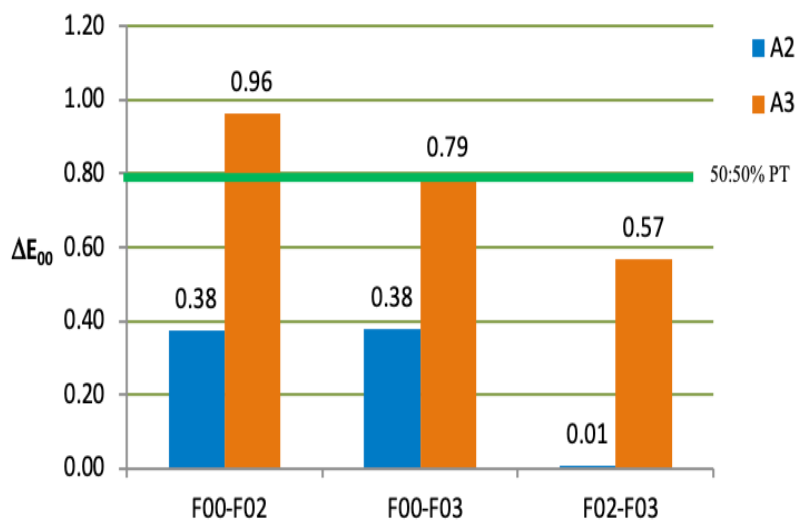

Figure 1. Color differences $\left(\Delta \mathrm{E}_{00}\right)$ between pairs of giomers evaluated over white background (50:50\% PT represent the visual perceptibility threshold for color differences).

The mean values of the translucency parameter are listed, along with the standard deviation values, both for the $\mathrm{A} 2$ and $\mathrm{A} 3$ colored materials, in table IV.
Table IV. Average translucency $\left(\mathrm{RTP}_{00}\right)$ values and standard deviations of giomer samples.

\begin{tabular}{l|c|c} 
& A2 & A3 \\
F00 & $30.34( \pm 0.88)$ & $29.64( \pm 1.64)^{\mathrm{b}}$ \\
F02 & $31.37( \pm 0.94)^{\mathrm{a}}$ & $30.79( \pm 1.02)^{\mathrm{c}}$ \\
F03 & $31.11( \pm 1.15)^{\mathrm{a}}$ & $30.1( \pm 1.26)^{\mathrm{b}, \mathrm{c}}$
\end{tabular}

* Same superscript letter in the same column indicate no significant difference $(\mathrm{p}>0.05)$.

The least translucent material was F00. The RTP of the A2 samples, was significantly different only between F02-F00 and F00-F03 ( $p<0.05)$. For A3 samples, significant differences were found only between F02-F00 materials $(\mathrm{p}<0.05)$, with F00 being the least translucent.

Differences in translucency between all pairs of materials with the same color designation are illustrated in figure 2 .

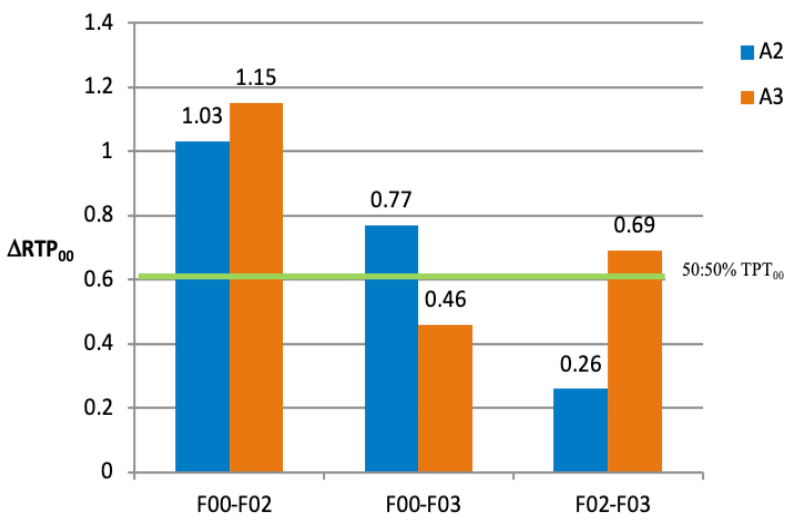

Figure 2. Differences in translucency $\left(\Delta \mathrm{RTP}_{00}\right)$ between giomers over white background $\left(50: 50 \% \mathrm{TPT}_{00}\right.$ represent the visual perceptibility threshold for differences in translucency).

The greatest differences in translucency were observed between F00 and F02 materials, for both A2 and A3 colored samples. These differences were above the perceptibility threshold; however, all the values were below the acceptability threshold.

Masking properties, expressed as color differences between the samples measured on the tested versus control backgrounds are presented in table $\mathrm{V}$.

Table V. Masking capacity of the tested giomers expressed as a color difference $\left(\Delta \mathrm{E}_{00}\right)$ between the sample measured over $\mathrm{A} 2$ or A3 background and the sample measured over C3 background.

\begin{tabular}{c|c|c} 
& A2 & A3 \\
F00 & $6.28( \pm 0.53)$ & $5.35( \pm 0.48)^{\mathrm{a}}$ \\
F02 & $5.92( \pm 0.38)$ & $5.48( \pm 0.59)^{\mathrm{a}}$ \\
F03 & $5.63( \pm 0.57)$ & $4.89( \pm 0.35)$
\end{tabular}

*Same superscript letter in the same column indicate no significant difference $(\mathrm{p}>0.05)$. 
The masking capacity of the A2 colored samples, was significantly different between all the three materials $(p<0.05)$. However, the masking capacity of the A3 colored samples, for the same background was significantly different only between F00- F03 and F02-F03 materials.

The color difference exceeded the values of PT and AT, in all circumstances.

\section{Discussion}

The purpose of this study was to assess the optical properties, expressed as CIEL*a*b* parameters, the translucency parameter, and the masking capacity of three different types of flowable giomers.

The null hypothesis, that no significant differences can be detected in the color coordinates, translucency and masking capacity between different flowable giomers of the same color designation, was partially rejected.

The differences in color coordinates were slightly greater for A3-shaded samples fabricated from the three commercial giomers. For both A2 and A3 shades, the "F03 low flow" material was found as having increased lightness. However, the color differences between the materials with the same shade designation were below the perceptibility threshold, except the differences calculated for F00-F02 of A3 shade. As a clinical relevance, these results suggest that in most cases there is an excellent color match among the materials tested and acceptable match for F00 Beautifil Flow Plus X and F02 Beautifil Flow in A3 shade. As a consequence, from an optical point of view, the same result is expected when using a certain designation of flowable giomer, which means that other physical characteristics have to be considered when choosing between the variants (handling properties, consistency, mechanical properties).

Considering the relative translucency values $\left(\mathrm{RTP}_{00}\right)$ previously reported for A3 shade 1-mm thick enamel and dentine composite resins (13.27-18.05 and 10.06-15.22) [26], the translucency of the giomers evaluated in this study was significantly higher (29.64-30.79).

The findings of Kim and Park [24,31] showed that the optical properties of the resin-based composites are the result of complex interactions of different factors. Several authors [24,32-35] have found that Bis-GMA (bisphenol-A diglycidyl methacrylate) in the matrix of RBCs (resin-based composites) had made these more translucent when compared to RBCs with TEGDMA/ UDMA (triethyleneglycol dimethacrylate / urethane dimethacrylate) in the matrix. The translucency parameter (TP) is also significantly influenced by the amount of filler in the RBCs composition; the higher the filler content, the lower the translucency parameter.

The fact that the F02 material (with a percentage of $20-30 \%$ Bis-GMA) proved to be the most translucent from the three analyzed is in accordance with the composition, the percentage listed by the producer for the amount of Bis-GMA for F00 and F03 being 10-20\%. In addition, the percentage of filler is different in the tested flowables giomers. In this respect, Lee [34] reported that TP decreased as the amount of filler increased for a given filler size. This would explain the high translucency of the flowable giomers, as flowable restoration materials have lower filler content (when compared to conventional ones) [18].

In addition, the results of the present study are in agreement with the clinical indications of each material. There is a clear influence of the filler percentage (listed by the producer) on the materials' translucency: $50-60 \%$ filler for the less translucent F00 and F03 and 40-50\% for F02.

The lightness was also highly correlated with the amount of filler. Oxides and pigments added to the mixture may influence the color and opacity parameters, in relation to the wavelength of visible light that they absorb and reflect [18].

The results of our findings support, from an optical point of view, the clinical indications for each material. The one with the least amount of filler and higher translucency (F02) is indicated predominantly for anterior restorations, where esthetics is most important. The least translucent and with minimal flowing capacity material, F00, with a higher percentage of filler can be subjected to higher stressbearing areas, like cusp and marginal ridges reconstruction.

Both F02 and F03 materials are indicated as base and liners, and this is likely due to the flowing capacity and the ability to properly cover the cavity walls, in addition to their fluoride releasing property.

It has been shown that materials of the same shade designation from different producers can display color differences, and this can account for differences of translucency [31,36-39].

However, we have to emphasize that, from a clinical point of view, given the differences in translucency between the tested materials, which range between the perceptibility and acceptability thresholds [26], the matching between the pairs of materials tested may be considered as acceptable; other properties than the level of translucency have to be considered for the selection of the flowable giomer with a certain color codification.

In this study, none of the differences between the same colored designated materials surpassed the acceptability threshold, but almost all surpassed the perceptibility threshold (except F00-F02 in A3 color, F02-F03 in A2 color).

In a clinical case, where the discolored substrate has to be concealed by the direct restorative material, it is important to take into consideration the qualities, the thickness, and the masking abilities of the utilized materials. Kim et al. [40] evaluated if opaque shade composite resins have the potential to mask black and gray backgrounds and reported that a $\mathrm{C} 4$ background was masked by resin thicknesses of $0.5-1 \mathrm{~mm}$, while a black background required a thickness of 1-2 $\mathrm{mm}$. 
According to our results, a thickness of $1 \mathrm{~mm}$ of flowable giomer cannot efficiently mask a C3-colored substrate. In all cases, the values of color differences between the samples measured over the $\mathrm{C} 3$ substrate and over a background identical in color with the tested materials were above the acceptability threshold. In other words, regardless of what material is used, in this thickness of $1 \mathrm{~mm}$, a C3 colored substrate would remain apparent, negatively influencing the esthetic outcome of the restoration. These results may be attributed to the increased translucency of the tested flowable. In the case of a dyschromic substrate, it is important and necessary to select a method to additionally hide it, considering the clinical characteristics of the case (to use an opaque liner, to increase the layer of flowable giomer, to combine giomers with different consistencies).

The clinical implications of the present study are that both the translucency and masking capacity of direct restoration materials should be considered in order to obtain the best clinical result with respect to esthetic and mechanical expectancies.

In the present study, only 1-mm thick samples were evaluated. Also, the only background used for evaluation of the masking capacity was a $\mathrm{C} 3$ shaded composite resin. Further studies should be conducted to evaluate the optical properties of other thicknesses of giomers, as well as their behavior on natural tooth backgrounds.

\section{Conclusions}

Within the limitations of the present in vitro study, it can be concluded that the color differences between the flowable giomers with the same designation were below the perceptibility threshold in most cases. In addition, they displayed increased lightness and translucency, with differences between the tested materials, which ranged between the perceptibility and acceptability thresholds for translucency. Although the A2 shaded samples had a lower masking capacity than the A3 samples, overall, all tested giomers had an unacceptable masking capacity for the C3 background (representing a grayish discolored background).

\section{Acknowledgements}

This study was supported by the Iuliu Hatieganu University of Medicine and Pharmacy, Cluj-Napoca, by the internal Project: Nr. 1680/75, of 19 January 2018. The statistical analysis in this study was done with the assistance and coordination of Ioan Cristian Chifu, Professor at the Department of Business, Babes-Bolyai University in ClujNapoca, Romania.

\section{References}

1. Lajnert V, Kovacevic Pavicic D, Pavlic A, Pokrajac-Bulian A, Spalj S. Smile Aesthetics Satisfaction Scale: development and validation of a new brief five-item measure of satisfaction with smile aesthetics in adults and the elderly. Int Dent J. 2018;68:162-170.

2. Rodrigues Cde D, Magnani R, Machado MS, Oliveira OB. The perception of smile attractiveness. Angle Orthod. 2009;79:634-639.

3. Chang CA, Fields HW Jr, Beck FM, Springer NC, Firestone AR, Rosenstiel S, et al. Smile esthetics from patients' perspectives for faces of varying attractiveness. Am J Orthod Dentofacial Orthop. 2011;140:e171-e180.

4. Della Bona A, Kelly JR. The clinical success of all-ceramic restorations. J Am Dent Assoc. 2008;139 Suppl:8S-13S.

5. Al-Ansari A, Ellakany P, Fouda S, Al-Sheikh R, El Tantawi M. Intention to seek esthetic dental treatment and the theory of planned behavior in Saudi dental students and the general population. J Prosthet Dent. 2020. doi: 10.1016/j. prosdent.2019.07.005.

6. Carossa S, Lombardo S, Pera P, Corsalini M, Rastello ML, Preti PG. Influence of posts and cores on light transmission through different all-ceramic crowns: spectrophotometric and clinical evaluation. Int J Prosthodont. 2001;14:9-14.

7. Schricker SR. Composite resin polymerization and relevant parameters. In: Eliades T, Brantley W, editors. Orthodontic Applications of Biomaterials. Woodheah Publishing; 2016, p.153-170.

8. Rajan G, Shouha P, Ellakwa A, Bhowmik K, Xi J, Prusty G. Evaluation of the physical properties of dental resin composites using optical fiber sensing technology. Dent Mater. 2016;32:1113-1123.

9. Itota T, Carrick TE, Yoshiyama M, McCabe JF. Fluoride release and recharge in giomer, compomer and resin composite. Dent Mater. 2004;20:789-795.

10. Xu X, Ling L, Wang R, Burgess JO. Formulation and characterization of a novel fluoride-releasing dental composite. Dent Mater. 2006;22:1014-1023.

11. Rusnac ME, Gasparik C, Irimie AI, Grecu AG, Mesaroş AŞ, Dudea D. Giomers in dentistry - at the boundary between dental composites and glass-ionomers. Med Pharm Rep. 2019;92:123-128.

12. Dionysopoulos D, Tolidis K, Gerasimou P, KoliniotouKoumpia E. Effect of preheating on the film thickness of contemporary composite restorative materials. J Dent Sci. 2014;9:313-319.

13. Harhash AY, ElSayad II, Zaghloul AGS. A comparative in vitro study on fluoride release and water sorption of different flowable esthetic restorative materials. Eur J Dent. 2017;11:174-179.

14. McCabe JF, Rusby S. Water absorption, dimensional change and radial pressure in resin matrix dental restorative materials. Biomaterials. 2004;25:4001-4007.

15. Jyothi K, Annapurna S, KumarAS, Venugopal P, Jayashankara C. Clinical evaluation of giomer- and resin-modified glass ionomer cement in class V noncarious cervical lesions: An in vivo study. J Conserv Dent. 2011;14:409-413. 
16. Gordan VV, Mondragon E, Watson RE, Garvan C, Mjör IA. A clinical evaluation of a self-etching primer and a giomer restorative material: results at eight years. J Am Dent Assoc. 2007;138:621-627.

17. Gordan VV, Blaser PK, Watson RE, Mjör IA, McEduard DL, Sensi LG, Riley JL 3rd. A clinical evaluation of a giomer restorative system containing surface prereacted glass ionomer filler: results from a 13-year recall examination. J Am Dent Assoc. 2014;145:1036-1043.

18. Yu B, Lee YK. Differences in color, translucency and fluorescence between flowable and universal resin composites. J Dent. 2008;36:840-846.

19. Sharma G, Wu W, Dalal EN. The CIEDE2000 colordifference formula: implementation notes, supplementary test data, and mathematical observations. Color Res Appl. 2005;30:21-30.

20. Igiel C, Lehmann KM, Ghinea R, Weyhrauch M, Hangx Y, Scheller H, et al. Reliability of visual and instrumental color matching. J Esthet Restore Dent. 2017;29:303-308.

21. Paravina RD, Ghinea R, Herrera LJ, Bona AD, Igiel $C$, Linninger $\mathrm{M}$, et al. Color difference thresholds in dentistry. $\mathrm{J}$ Esthet Restor Dent. 2015;27 Suppl 1:S1-S9.

22. Paravina RD, Pérez MM, Ghinea R. Acceptability and perceptibility thresholds in dentistry: A comprehensive review of clinical and research applications. J Esthet Restor Dent. 2019;31:103-112.

23. Khashayar G, Bain PA, Salari S, Dozic A, Kleverlaan CJ, Feilzer AJ. Perceptibility and acceptability thresholds for color differences in dentistry. J Dent. 2014;42:637-644.

24. Kim D, Park SH. Color and Translucency of Resin-based Composites: Comparison of A-shade Specimens Within Various Product Lines. Oper Dent. 2018;43:642-655.

25. Piccoli YB, Lima VP, Basso GR, Salgado VE, Lima GS, Moraes RR. Optical Stability of High-translucency Resinbased Composites. Oper Dent. 2019;44:536-544.

26. Salas M, Lucena C, Herrera LJ, Yebra A, Della Bona A, Pérez MM. Translucency thresholds for dental materials. Dent Mater. 2018;34:1168-1174.

27. Salgado VE, Rego GF, Schneider LF, Moraes RR, Cavalcante LM. Does translucency influence cure efficiency and color stability of resin-based composites? Dent Mater. 2018;34:957-966.
28. Mikhail SS, Schricker SR, Azer SS, Brantley WA, Johnston WM. Optical characteristics of contemporary dental composite resin materials. J Dent. 2013;41:771-778.

29. Pérez MM, Ghinea R, Ugarte-Alván LI, Pulgar R, Paravina RD. Color and translucency in silorane-based resin composite compared to universal and nanofilled composites. J Dent. 2010;38 Suppl 2:e110-e116.

30. Ryan EA, Tam LE, McComb D. Comparative translucency of esthetic composite resin restorative materials. J Can Dent Assoc. 2010;76:a84.

31. Kim DH, Park SH. Evaluation of resin composite translucency by two different methods. Oper Dent. 2013;38:E1-E15.

32. Azzopardi N, Moharamzadeh K, Wood DJ, Martin N, van Noort R. Effect of resin matrix composition on the translucency of experimental dental composite resins. Dent Mater. 2009;25:1564-1568.

33. Manojlovic D, Dramićanin MD, Lezaja M, Pongprueksa P, Van Meerbeek B, Miletic V. Effect of resin and photoinitiator on color, translucency and color stability of conventional and low-shrinkage model composites. Dent Mater. 2016;32:183191.

34. Lee YK. Influence of filler on the difference between the transmitted and reflected colors of experimental resin composites Dent Mater. 2008;24:1243-1247.

35. Lim YK, Lee YK, Lim BS, Rhee SH, Yang HC. Influence of filler distribution on the color parameters of experimental resin composites. Dent Mater. 2008;24:67-73.

36. Ikeda T, Sidhu SK, Omata Y, Fujita M, Sano H. Colour and translucency of opaque-shades and body-shades of resin composites. Eur J Oral Sci. 2005;113:170-173.

37. Lee YK, Lim BS, Rhee SH, Yang HC, Powers JM. Color and translucency of A2 shade resin composites after curing, polishing and thermocycling. Oper Dent. 2005;30:436-442.

38. Sidhu SK, Ikeda T, Omata Y, Fujita M, Sano H. Change of color and translucency by light curing in resin composites. Oper Dent. 2006;31:598-603.

39. Nakamura T, Saito O, Mizuno M, Tanaka H. Changes in translucency and color of particulate filler composite resins. Int J Prosthodont. 2002;15:494-499.

40. Kim SJ, Son HH, Cho BH, Lee IB, Um CM. Translucency and masking ability of various opaque-shade composite resins. J Dent. 2009;37:102-107. 